\title{
The Impact of Breast Volume on Lung and Heart Radiation Doses After Breast Conserving Surgery
}

\author{
Eman. A.T \\ Radiotherapy and nuclear medicine, Oncology department, Menofia University
}

\begin{abstract}
Aim: evaluation of the impact of breast volume difference on lung and heart radiation doses received from tangential fields after breast conserving surgery and also evaluation of dose distribution within the target.

Material and methods: 15 patients with early breast cancer treated with breast conserving surgery were selected to undergo CT imaging and 3D treatment plane. The dose volume histograms for the Clinical Target Volume (CTV), both lungs and the heart were then calculated and printed showing the maximum, mean, median dose, including the standard deviation received by each. The patients were grouped according to the breast volume into small breast patients with breast volume 400-700CC and large breast patients with volume more than 1100CC. Nine patients had left sided breast cancer $(9 / 15)$, six patients had large breast and three had small breast. Six of them had right sided breast cancer (6/15), three of them had large breast and the other three had small breast.

Results: Dose heterogeneity within the breast CTV was high, 8 of 9 patients with large breast volume received maximum doses of $110 \%$ or higher and one patient of them received maximum dose of $120 \%$ compared to only 2 patients of 6 patients with small breast volume received maximum doses of $110 \%$. Dose Volume Histogram (DVH) data: the mean dose for small breast volume was $99.9 \pm 0.9$ compared to $99.5 \pm 1.6$ for large breast volume and the difference was not statistically significant $(P>0.05)$.

The maximum dose was $109.3 \pm 0.9$ for small breast volume and $115.2 \pm 3.7$ for large breast volume and the difference was statistically highly significant $(P<0.001)$. The mean percentage dose to the ipsilateral lung was $15.8 \pm 3.3$ for small breast volume compared to $20.11 \pm 6.82$ for large breast volume and the difference was not statistically significant $(P>0.05)$. The mean percentage volume of the heart that received a dose of $24 \mathrm{~Gy}$ or more was $2 \pm 1.3$ for small breast volume compared to $6 \pm 4.25$ for large breast volume and the difference was not statistically significant $(P>0.05)$.
\end{abstract}

Key words: Breast volume- conservative surgery-maximum dose-lung-heart.

Corresponding Author: Eman Abdelrazek $\quad$ E-mail: egamaleldeen@yahoo.com

\section{INTRODUCTION}

Breast cancer is the most common cancer in females and is second after the lung cancer as a cause of cancer mortality in females. Conservative Surgery (CS) and Radiotherapy (RT) has become an accepted alternative to mastectomy for treatment of patients with early breast cancer (Matthew et al.). There is a significantly decreased incidence of breast recurrences after tangential irradiation following breast conserving surgery in patient with early breast cancer ${ }^{1}$.

The goal of radiation therapy for early breast cancer is to deliver a dose distribution that will result in a high level of local control while minimizing the risk of normal tissue damage. The target volume generally includes the breast \pm chest wall (the chest wall isn't a target in T1,2 N0) and in some cases, the draining lymph nodes ${ }^{2}$.

The breast is a difficult structure to irradiate in a homogenous manner. Firstly, it has a complex 3D shape and is located at the body- air interface, often with rapid changes in contour and tissue separation; together with much inter patient variation in breast size and shape, both of which may be modified further by surgery. This can present problems in terms of beam obliquity and increased radiation build- up in the subcutaneous tissue particularly on the sagital centre line of the breast. Secondly, the dose limiting organs i.e lung and heart (in case of left breast cancer), are in close proximity to the under surface of the breast and chest wall ${ }^{3}$.

Factors associated with increased risk of cardiovascular morbidity after breast cancer radiotherapy include volume of irradiated heart (which is mainly a consequence of radiotherapy technique and choice of target volumes) total radiation dose, fractionation, the use of cardiotoxic chemotherapy and the coexistence of other recognized risk factors for cardiovascular disease ${ }^{4}$. 


\section{AIM}

to evaluate the impact of breast volume difference on lung and heart radiation doses received from tangential field after breast conservative surgery and evaluation of the dose distribution within the target.

\section{MATERIALS AND METHODS}

Fifteen patients with early breast cancer treated with breast conserving surgery were selected to undergo CT imaging and 3D treatment plane. All patients are eligible for radical radiotherapy.

Nine patients had left sided breast cancer $(60 \%)$ and six patients had right sided breast cancer (40\%).

Patients were positioned supine with the head, neck and upper chest on an angle board placed on the top of CT table with the ipsilateral arm out to the side with the hand above the head and other arm extended beside the patient on the CT Table.

Prior to CT scanning the treatment volume was marked and lead wires were placed at the superior, inferior, medial and lateral margins.

One $\mathrm{cm}$ axial $\mathrm{CT}$ images were acquired from above the lung apices to below lowest limit of visible lung tissue.

The images were transferred to 3D planning system by a tape.

The breast, both lungs and heart were outlined on each CT image.

The target was defined on each image, the Clinical Target Volume (CTV) is considered to be the entire breast volume and chest wall. The Planning Target Volume (PTV) is defined as the CTV plus a $2 \mathrm{~cm}$ additional margin to account for limitations of the treatment technique.

Patients were treated with photon irradiation on a 6MV Linear accelerator. The prescribed dose was $50 \mathrm{~Gy}$, fraction size was $2 \mathrm{~Gy} /$ day (25 fractions).

The medial field entrance point was consistently the midline of the chest wall, the lateral field entrance point consistently being the mid-axillary line.

The dose volume histograms for the clinical target volume, ipsilteral lung and the heart were then calculated and printed showing the maximum, mean, median dose, including the standard deviation received by each.

The lung is evaluated either by the central lung distance included in the field or the V20.

Ramsey et al., chose a volume of 400-700CC to corresponding to small breasts, $700-1100 \mathrm{CC}$ to corresponding to medium-sized breasts and a volume of more than $1100 \mathrm{CC}$ to corresponding to large breasts 5 . Accordingly, our patients were grouped according to the breast volume into small breast patients with breast volume 400-700CC and large breast patients with breast volume more than $1100 \mathrm{CC}$.

Nine patients had left sided breast cancer (9/15), six of them had large breast and three had small breast.

Six patients had right sided breast cancer (6/15), three of them with large breast and the other three with small breast.

\section{RESULTS}

\section{Results were obtained from:}

1. Comparing isodose distribution of the target volume for small and large breast volumes.

2. Studying Dose Volume Histogram (DVH) of the small and large breast as regard doses to target, lung, and heart.

3. Comparison of the isodose distributions of the target between small and large breast volume.

Dose heterogeneity within the breast CTV was high with 8 patients of 9 patients with large breast volume receiving maximum doses of $110 \%$ or higher and one patient with maximum dose of $120.2 \%$ compared to only 2 patients of 6 patients with small breast volume receiving maximum doses of $110 \%$.

The dose heterogeneity within the breast could be corrected by using high energy beam instead of $6 \mathrm{MV}$ beam.

According to the ICRU 62 report: The dose within the target should be in the range of $107 \%$ and $95 \%$, so the dose above or below is considered heterogeneity.

\section{Dose volume histogram (DVH) data:}

The percentage dose distribution to the target from tangential fields: The maximum dose was $109.3+0.9$ for small breast volume and 115.2+3.7 for large breast volume and the difference was statistically highly significant $(P<0.001)$. The mean dose for small breast 
volume was $99.9+0.9$ compared to $99.5+1.6$ for large breast volume and the difference was not statistically significant $(P>0.05)$.

The mean breast volume that received more than $110 \%$ of the prescribed dose was $0.1 \pm 0.24$ for small breast volume patients and $2.2 \pm 2.25$ for large breast volume patients. The difference was statistically highly significant $(P<0.001)$.

The mean percentage dose to the ipsilateral lung was $15.8 \pm 3.3(7.9 \pm 1.65 \mathrm{~Gy})$ for small breast volume compared to $20.11 \pm 6.82(10.06 \pm 3.41 \mathrm{~Gy})$ for large breast volume and the difference was not statistically significant $(P>0.05)$.

The mean percentage volume of irradiated ipsilateral lung was $7.2 \pm 3.5 \mathrm{CC}$ for small breast volume compared to $10.4 \pm 5.65 \mathrm{CC}$ for large breast volume and the difference was not statistically significant $(P>0.05)$.

Table 1: Maximum and mean doses to the target in small breast volume patients.

\begin{tabular}{lcccc}
\hline $\begin{array}{l}\text { Patient code } \\
\text { number }\end{array}$ & $\begin{array}{c}\text { Right/ } \\
\text { Left }\end{array}$ & $\begin{array}{c}\text { Maximum } \\
\text { dose }\end{array}$ & $\begin{array}{c}\text { Minimal } \\
\text { dose }\end{array}$ & $\begin{array}{c}\text { Mean } \\
\text { dose }\end{array}$ \\
\hline 1 & Rt & 109.4 & 91.6 & 100.5 \\
\hline 2 & Lt & 109.6 & 89.8 & 99.7 \\
\hline 3 & Lt & 110.3 & 86.9 & 98.6 \\
\hline 5 & Rt & 108.9 & 91.3 & 100.1 \\
\hline 6 & Lt & 110 & 88.4 & 99.2 \\
\hline
\end{tabular}

Table 2: Maximum and mean doses to the target in large breast volume patients.

\begin{tabular}{lcccc}
\hline $\begin{array}{l}\text { Patient code } \\
\text { number }\end{array}$ & $\begin{array}{c}\text { Right/ } \\
\text { Left }\end{array}$ & $\begin{array}{c}\text { Maximum } \\
\text { dose }\end{array}$ & $\begin{array}{c}\text { Minimal } \\
\text { dose }\end{array}$ & $\begin{array}{c}\text { Mean } \\
\text { dose }\end{array}$ \\
\hline 7 & $\mathrm{Lt}$ & 116.5 & 83.3 & 99.9 \\
\hline 8 & $\mathrm{Lt}$ & 112.1 & 87.1 & 99.6 \\
\hline 9 & $\mathrm{Rt}$ & 115.7 & 82.9 & 99.3 \\
\hline 10 & $\mathrm{Lt}$ & 115.2 & 87.6 & 101.4 \\
\hline 11 & $\mathrm{Lt}$ & 113.9 & 84.3 & 99.1 \\
\hline 12 & $\mathrm{Lt}$ & 117.7 & 80.9 & 99.3 \\
\hline 13 & $\mathrm{Rt}$ & 120.2 & 71.4 & 95.8 \\
\hline 14 & $\mathrm{Rt}$ & 118.0 & 81.2 & 99.6 \\
\hline 15 & $\mathrm{Lt}$ & 107.6 & 94.8 & 101.2 \\
\hline
\end{tabular}

The mean percentage dose to the heart was $10.87 \pm 5.02$ for small breast volume compared to $7.7 \pm 4.1$ for large breast volume and the difference was not statistically significant $(P>0.05)$.

The mean percentage volume of the heart that received a dose of $24 \mathrm{~Gy}$ or more was $2 \pm 1.3$ for small breast volume compared to $6 \pm 4.25$ for large breast volume and the difference was not statistically significant $(P>0.05)$.

\section{Statistical analysis:}

Quantitative data is shown as mean, SD and range while Qualitative data is expressed as frequency and percent at $95 \%$ confidence interval $(95 \% \mathrm{CI})$. Student t-test and Mann Whitney test was used to compare means and SD of 2 sets of quantitative normally and not normally distributed data, respectively. $\mathrm{P}$ (probability) value is considered to be statistically significance if it is less than 0.05

Table 3: Maximum and mean doses to breast.

\begin{tabular}{lcccc}
\hline \multirow{2}{*}{ Studied variables } & \multicolumn{2}{c}{ Breast volume } & & \\
\cline { 2 - 3 } & $\begin{array}{c}\text { Small } \\
\mathbf{N}=\mathbf{6}\end{array}$ & $\begin{array}{c}\text { Large } \\
\mathbf{N}=\mathbf{9}\end{array}$ & \multirow{2}{*}{ - test } & $\boldsymbol{P}$ - value \\
\cline { 2 - 3 } & Mean \pm SD & Mean \pm SD & & \\
\hline Max dose to breast & $109.3 \pm 0.9$ & $115.2 \pm 3.71$ & 3.8 & $0.001^{* *}$ \\
\hline Mean dose to breast & $99.9 \pm 0.9$ & $99.5 \pm 1.6$ & 0.55 & $>0.05$ \\
\hline
\end{tabular}

Table 4: The mean breast volume that received more than $110 \%, 107-110,95-107,80-90$ and less than $95 \%$ of the prescribed dose.

\begin{tabular}{lcccc}
\hline & \multicolumn{2}{c}{ Breast volume } & & \\
\cline { 2 - 3 } Studied variables & $\begin{array}{c}\text { Small } \\
\mathbf{N}=\mathbf{6}\end{array}$ & $\begin{array}{c}\text { Large } \\
\mathbf{N}=\mathbf{9}\end{array}$ & $\begin{array}{c}\text { Mann } \\
\text { Whitney } \\
\text { test }\end{array}$ & $\boldsymbol{P}$ - value \\
\cline { 2 - 3 } & Mean \pm SD & Mean \pm SD & & \\
\hline $\begin{array}{l}\text { Breast volume } \\
\text { received more } \\
\text { than } 110 \%\end{array}$ & $0.1 \pm 0.24$ & $2.2 \pm 2.25$ & 2.7 & $<0.001^{* *}$ \\
\hline $\begin{array}{l}\text { Breast volume } \\
\text { received } \\
(107-110 \%)\end{array}$ & $6.17 \pm 3.66$ & $6.69 \pm 3.39$ & 0.35 & $>0.05$ \\
\hline $\begin{array}{l}\text { Breast volume } \\
\text { received } \\
(95-107 \%)\end{array}$ & $81.17 \pm 4.02$ & $76.33 \pm 5.21$ & 1.83 & $>0.05$ \\
\hline $\begin{array}{l}\text { Breast volume } \\
\text { received less } \\
\text { than 95\% }\end{array}$ & $12.57 \pm 2.43$ & $14.76 \pm 4.06$ & & \\
\hline
\end{tabular}


Table 5: The mean percentage volume of irradiated ipsilateral lung and The mean percentage dose to the ipsilateral lung.

\begin{tabular}{lcccc}
\hline & \multicolumn{2}{c}{ Breast volume } & & \\
\cline { 2 - 3 } Studied variables & Small & Large & t- test & P- value \\
\cline { 2 - 3 } & Mean \pm SD & Mean \pm SD & & \\
\cline { 2 - 3 } $\begin{array}{l}\text { \% volume } \\
\text { of irradiated } \\
\text { ipsilateral lung }\end{array}$ & $7.2 \pm 3.5$ & $10.4 \pm 5.65$ & 1.23 & $>0.05$ \\
\hline $\begin{array}{l}\text { Minimum dose to } \\
\text { ipsilateral lung }\end{array}$ & $1.3 \pm 0.14$ & $1.7 \pm 0.24$ & 3.7 & $<0.001^{* *}$ \\
\hline $\begin{array}{l}\text { Maximum dose to } \\
\text { ipsilateral lung }\end{array}$ & $104 \pm 2.26$ & $104 \pm 2.98$ & 0.02 & $>0.05$ \\
\hline $\begin{array}{l}\text { Mean dose to } \\
\text { ipsilateral lung }\end{array}$ & $15.8 \pm 3.3$ & $20.11 \pm 6.02$ & 1.6 & $>0.05$ \\
\hline $\begin{array}{l}\text { Median dose to } \\
\text { ipsilateral lung }\end{array}$ & $3.55 \pm 0.74$ & $4.74 \pm 0.75$ & 3.02 & $<0.05^{*}$ \\
\hline
\end{tabular}

Table 6: The mean percentage dose to the heart.

\begin{tabular}{lcccc}
\hline \multirow{2}{*}{ Studied variables } & \multicolumn{2}{c}{ Breast volume } & & \\
\cline { 2 - 3 } & Small & Large & \multirow{2}{*}{ - test } & $\boldsymbol{P}$ - value \\
\cline { 2 - 3 } & Mean \pm SD & Mean \pm SD & & \\
\hline Heart volume & $537.7 \pm 106.6$ & $560 \pm 115.8$ & 0.28 & $>0.05$ \\
\hline $\begin{array}{l}\text { Minimum doses } \\
\text { of radiation }\end{array}$ & $1.7 \pm 0.38$ & $1.9 \pm 0.34$ & 0.94 & $>0.05$ \\
\hline $\begin{array}{l}\text { Maximum doses } \\
\text { of radiation }\end{array}$ & $100.4 \pm 1.92$ & $101.1 \pm 6.03$ & 0.18 & $>0.05$ \\
\hline $\begin{array}{l}\text { Median doses of } \\
\text { radiation }\end{array}$ & $3.97 \pm 0.42$ & $3.63 \pm 0.62$ & 0.82 & $>0.05$ \\
\hline $\begin{array}{l}\text { Median dose to } \\
\text { ipsilateral lung }\end{array}$ & $3.55 \pm 0.74$ & $4.74 \pm 0.75$ & 3.02 & $<0.05^{*}$ \\
\hline
\end{tabular}

Table 6: The mean percentage volume of the heart that received a dose of $24 \mathrm{~Gy}, 40 \mathrm{~Gy}$ and $45 \mathrm{~Gy}$.

\begin{tabular}{|c|c|c|c|c|}
\hline \multirow{3}{*}{ Studied variables } & \multicolumn{2}{|c|}{ Breast volume } & \multirow{3}{*}{$\begin{array}{c}\text { Mann } \\
\text { Whitney } \\
\text { test }\end{array}$} & \multirow{3}{*}{$P$-value } \\
\hline & $\begin{array}{c}\text { Small } \\
\mathbf{N}=3\end{array}$ & $\begin{array}{c}\text { Large } \\
N=6\end{array}$ & & \\
\hline & Mean \pm SD & Mean \pm SD & & \\
\hline $\begin{array}{l}\text { Percent of heart } \\
\text { volume that } \\
\text { received } 24 \mathrm{~Gy}\end{array}$ & $2 \pm 1.3$ & $6 \pm 4.25$ & 1.3 & $>0.05$ \\
\hline $\begin{array}{l}\text { Percent of heart } \\
\text { volume that } \\
\text { received } 40 \mathrm{~Gy}\end{array}$ & $0.97 \pm 1$ & $3.02 \pm 2.5$ & 1.18 & $>0.05$ \\
\hline $\begin{array}{l}\text { Percent of heart } \\
\text { volume that } \\
\text { received } 45 \mathrm{~Gy}\end{array}$ & $0.03 \pm 0.06$ & $0.35 \pm 0.76$ & 0.31 & $>0.05$ \\
\hline $\begin{array}{l}\text { Mean dose of } \\
\text { radiation }\end{array}$ & $10.87 \pm 5.02$ & $7.7 \pm 4.1$ & 1.29 & $>0.05$ \\
\hline SD & $18.23 \pm 9.96$ & $12.42 \pm 8.63$ & 1.17 & $>0.05$ \\
\hline
\end{tabular}

\section{DISCUSSION}

External beam radiotherapy to the breast using a standard tangential beam arrangement continues to be an efficacious technique to reduce the local failure rate in patients undergoing breast conservation therapy ${ }^{6}$. Large clinical trials and institutional reports have documented local failure rates of approximately $10 \%$ with over 10 years of follow-up when tangential breast irradiation is given following lumpectomy? This low local failure rate is likely to be a result of adequate irradiation with respect to dose and volume. Local failures are at least 3.5 times more common without radiation and twice as common with partial breast irradiation when compared with whole breast irradiation ${ }^{8}$.

In this study: Dose heterogeneity within the breast CTV was high with 8 patients of 9 patients with large breast volume receiving maximum doses of $110 \%$ or higher and one patient with maximum dose of $120.2 \%$ compared to only 2 patients of 6 patients with small breast volume receiving maximum doses of $110 \%$. The mean dose for small breast volume was $99.9 \pm 0.9$ compared to $99.5 \pm 1.6$ for large breast volume and the difference was not statistically significant $(P>0.05)$.

The maximum dose was $109.3 \pm 0.9$ for small breast volume and $115.2 \pm 3.7$ for large breast volume and the difference was statistically highly significant $(P<0.001)$. The mean percentage dose to the ipsilateral lung was $15.8 \pm 3.3$ for small breast volume compared to $20.11 \pm 6.82$ for large breast volume and the difference was not statistically significant $(P>0.05)$. The mean percentage volume of the heart that received a dose of $24 \mathrm{~Gy}$ or more was $2 \pm 1.3$ for small breast volume compared to $6 \pm 4.25$ for large breast volume and the difference was not statistically significant $(P>0.05)$.

Neal et al., evaluated the effect of breast size on dose homogeneity, twenty women underwent planning CT scan of the thorax. A three-dimensional treatment plan was devised for each patient using a standard technique of isocentric medial and lateral wedged tangential fields. Three-dimensional dose distributions were derived using an equivalent path length inhomogenity correction and cumulative dose-volume histogram data calculated. Analysis of the DVHs for each patient reveals that $0.2-23.8 \%$ of the breast received an absorbed dose outside the desired $95-105 \%$ of that prescribed at the isocentre. The degree of dose heterogeneity was most strongly correlated with breast volume $(r=0.70,95 \%$ confidence interval (C.I.) $0.37-0.87)$. There was also a positive correlation for breast dose heterogeneity versus brassiere (bra) cup size (Spearman rankcorrelation $P=0.62$ ), breast area 
$(r=0.39,95 \%$ C.I. $-0.06-0.71)$ and chest wall separation $(r=0.31,95 \%$ C.I. $-0.15-0.66)$. Nearly the same results as our study. Finally, they conclude that breast size is an important determinant of dose heterogeneity within the breast $^{9}$.

Different results were found by Bhatnagar ${ }^{10}$ who evaluate the relationship between the primary breast volume and dose received by the ipsilateral lung, heart (for left-breast cancers) and contralateral breast during primary breast irradiation using IntensityModulated Radiation Therapy (IMRT). Sixty-five patients with breast carcinoma were treated using 6-MV photons with IMRT following breast conserving surgery. All patients had a treatment planning CT scan. The primary breast, ipsilateral lung and heart were contoured on the axial CT slices. They found that the mean volume of the primary irradiated breast was $1167.9 \mathrm{cc}$. As a percentage, the mean ipsilateral lung, heart and contralateral breast doses were $11.2 \%, 6.1 \%$ and $7.2 \%$, respectively. The primary breast volume positively correlated with the contralateral breast dose $(P<0.0005)$. There was no significant correlation between the breast volume and the ipsilateral lung or heart dose $(P=0.463$ and 0.943 , respectively). They concluded that the primary breast size significantly affects the scatter dose to the contralateral breast but not the ipsilateral lung or heart dose when using IMRT for breast irradiation. This difference may be attributed to two causes. Firstly, the use of IMRT. Secondarily, the larger number of patients.

\section{CONCLUSION}

For breast cancer patients with small breast volume who underwent conservative surgery and need post operative radiotherapy, there were accepted dose distribution within the target and accepted lung and heart doses. But breast cancer patients with large breast volume or pendulous breast should be irradiated with new techniques as prone position or the use of IMRT. The other option is surgical through Superior pedicle mammoreduction but this surgical reduction need to operate upon both breasts for cosmetic results.

\section{REFERENCES}

1. Jennifer F. Waljee, Emily S. Hu, Lisa A. Newman and Amy K. Alderman: Predictors of breast asymmetry after breast-conserving operation for breast cancer. J Am Coll Surg. 2008; 206: 273-280.

2. Jeroen Buijsen, Jos J. Jager Janneke Bovendeerd, Robert Voncken, Jacques H. Borger, Liesbeth J. Boersma, Lars H. P. Murrer and Philippe Lambin: Prone breast irradiation for pendulous breasts. Radiotherapy and Oncology 82 (2007) 337-340.

3. Ian Kunkler: Adjuvant irradiation for breast cancer. Modern radiotherapy techniques should reduce cardiovascular mortality. 2000 BMJ 320; 1485-1486.

4. Elzbieta Senkus-Konefka and Jacek Jassem: Cardiovascular effects of breast cancer radiotherapy. Cancer treatment reviews (2007) 33, 578-593.

5. Ramsey CR, Chase D, Scaperoth D, Awood D, Oliver A.Improved dose homogeneity to the intact breast using three-dimensional treatment planning: 2000, 25: 1-6.

6. Anees B. Chagpar, Kelly M. McMasters, Charles R. Scoggins, Robert CG Cynthia Thoene and Michael J. Edwards: The use of radiation therapy after breast conserving surgery in hormonally treated breast cancer patients is dependent on patient age, geographic region and surgery specialty. The American Journal of Surgery.

7. Matthew J. Krasin, Anne Mc Call, Stephanie King, Mary Olson and Bahman Emami: Evaluation of a standard breast tangent technique: A dose volume analysis of tangential irradiation using three dimensional tools. 2000 Int J. Radiation Oncology Biol. Phys, vol. 47, No. 2,pp. 327-333.

8. Naoto Shikama, Masahiko Oguchi, Shusuke Sone et al: Radiotherapy following mastectomy: indication and contraindication of chest wall irradiation. Int J of Radiation Oncology-Biology-Physics, Vol. 44 (5) 1999 pp. 991-996.

9. Neal A.J, Torra M, Helyerb S and Yamoldb J.R : Correlation of breast dose heterogeneity with breast size using 3D CT planning and dose-volume histograms. Radiotherapy and oncology 34 (1995) 210-218.

10. Bhatnagar AK, Heron DE, Deutsch M, Brandner E, Wu A, Kalnickis: Does breast size affect the scatter dose to the ipsilateral lung, heart, or contralateral breast in primary breast irradiation using intensity-modulated radiation therapy (IMRT)? Am J Clin Oncol 2006 Feb;29(1):80-4. 